\title{
A Brief Talk on How to Actively Adapt to Urbanization Development and Promote New Citizens' Quality Education: A Case Study of Bao'an District, Shenzhen
}

\author{
Min-Hua LIANG ${ }^{1,2}$ and Qian ZHANG $^{3,4, *}$ \\ ${ }^{1}$ Faculty of Management and Economics, Tianjin University, Tianjin 300072, China \\ ${ }^{2}$ School of management, Tianjin University, Tianjin 300072, China \\ ${ }^{3}$ Bureau of Public Works and Longgang Shenzhen Municipality, Shenzhen 518172, P. \\ R. China \\ ${ }^{4}$ Environmental Science \& Engineering Research Center, Harbin Institute of \\ Technology Shenzhen Graduate School, Shenzhen 518055, P. R. China
}

Keywords: Urbanization, New citizens, Quality education.

\begin{abstract}
In this paper, take Bao'an District, Shenzhen as the case, we summarized and analyzed the regional governments how to take idea as precursor, strengthen institution and mechanism innovation and persist people-oriented to promote new citizens' scientific and culture quality, civilized manners, professional skills and qualities in every aspect and elevate new citizens' happiness, therefore, to serve regional industry and economic and social development.
\end{abstract}

\section{Introduction}

Since China's reform and opening, with the industrialization and urbanization speeds up, more and more surplus rural transfer to urban. In this process, a special social group named migrant worker is formed. Migrant workers are special because they are not urban residents, but also have big difference with farmers. Due to the influence of modern urban civilization in living style and ideological and cultural conception, many migrant workers have a strong desire to urban life, while they would confront with many difficulties in current environment. Qingdao first renamed migrant workers to the "new citizens" and their children are called the "new citizens' children" since February 15th, 2006. The "new citizens" are unified management with city's residents and they could enjoy insurance, mortgage, driving tests, travel abroad and children entering school when they obtain temporary residence permits. The concept of "new citizens" in Bao'an District, Shenzhen has a broader definition in our studies, including residents from "County-to-District", "Village-to-Community" and migrant workers. Currently, the actual management of new citizens is more than 5 million in Bao'an District and the registered population is only 379,900 . In order to meet the demand of urbanization process, adjust and optimize the structure of industry and speed up the city modernization, Bao'an District insist on carry out quality education mainly in migrant workers and "Village-to-Community" residents since 2007. New ideas and new ways are actively explored new citizens' quality education during the rapid development of urbanization and remarkable social effect is achieved. The main measure and practice are summarized as follows. 
First, Persist People-oriented As Core Idea and Take People Quality Improvement As Urbanization Foundation Project

Philosophy and understanding are often forerunner and precondition in correctly solving problems. Bao'an District adhered to take the advanced science philosophy as guidance and ensured the new citizens education in the right direction during the process of carrying out new citizens' quality education.

\section{Persist People-oriented Concept, Realize the Core Shift from Materials Modemization to Human's Modernization}

"The Decision on Major Issues Concerning Comprehensively Deepening Reforms" in the Third Plenary Session of the $18^{\text {th }}$ CPC Central Committee has emphasized that we should adhere to the new urbanization with Chinese characteristics and promote the human-centered urbanization. Started from this century, although the industrial structure and occupational structure residents have completed transformation and upgrading and aboriginal household registration system and resident status has also changed, the quality of new citizens in Bao'an District may not achieve the quality of urban residents. Part of aborigines with "rich pocket" wants to be freeloaders and most of migrant workers come to Bao'an District just for money to escape from poverty, so they all lack of urban consciousness. In this case, the new citizens could not take heavy responsibilities for Bao'an District modernization as the builders and pioneers. In order to promote the process of rapid urbanization, turn the population pressure to human resource advantage, change regional population to strong human resources area, and foster the modernization and internationalization new citizens, district government considered the situation and decisively enacted a first document named "The advice on full comprehensive implementation of quality engineering" in 2007. The document clearly put forward to carry out quality promotion in head persons like party and government cadre and public officials, backbones like professionals and enterprise managers, and main bodies like community cadres, community resident and labor workers. The policy placed citizens' quality modernization promotion, economy development and environment protection on the same height, which highlighted the core ideology that urbanization should base on human orientation.

\section{Modem Civilization As a Guiding Principle, Help the "New Citizens" Transform from Agriculture Civilization to Modern Civilization}

Bao'an District developed education in new citizens and always adhered to take city consciousness, urban civilization, industrial civilization and production specifications, city life and homeland consciousness, ethical awareness and behavior habits, as first and basic content to educate. They penetrated concept consciousness, communicative manners, living style and behavior habits of the urban civilization to new citizens' daily life and things doing. They also helped new citizens including indigenous and migrant workers to learn civilized language, do civilized things and be civilized persons, and gradually changed bad habits and uncivilized speech and behaviors.

\section{Adhere to the Concept of Inclusive Development, Focus on Improving the Overall New Citizens' Quality, Including Migrant Workers and Indigenous}

Shenzhen is an immigrant city, including our Bao'an District. Migrant workers in Bao'an District have accounted for more than $90 \%$ and they have become the main force in secondary and service industry who are undoubtedly the main creators of material wealth and spiritual 
wealth. Hence, district government should not only help do well in educational training and improve their overall quality with coordination and cooperation, but also relate to the big problems including the implementation of fairness doctrine and share the achievement of reform and opening and modernization construction.

You are the Shenzhen person once you come here! This unpretentious slogan could be seen everywhere in Shenzhen which make outsiders feel particularly close. In a simplest case, every 65 years foreign old man in Shenzhen could possess a card to enjoy free bus and metro, which shows the concept of inclusive development.

\section{Second, Be Clear the New Citizens' Quality Standards and Construct Reasonable Curriculums}

\section{Formulate Quality Standards, Clear Education Specifications for New Citizens}

In 2012, "Three years action plan on promoting Bao'an District modern citizens quality" further proposed six aspects of quality standards to provide a fundamental basis and management practice for the development of new citizens' education. The first is legal and moral qualities, which are the core qualities. Focus on helping people develop good personal ethics, family virtues, professional ethics, and social ethics, familiar with basic legal knowledge, and consciously obey laws and regulation and safeguard their rights according to laws. The second is the scientific and cultural qualities, which are the basis qualities. Focus on popularizing scientific and cultural knowledge. The third is professional skill quality, which is the basic quality. Focus on improving the professional ability of the position of the general public, capability of seeking and creating employment and basic safety protection skills. In addition, other qualities such as literacy and health qualities of modern civilization are also important.

\section{Construct Curriculums, Provide Teaching Norms for the New Citizens Education}

Based on the new citizens quality standards, Bao'an District have developed a number of new curriculum materials for new citizens' quality education with more than 60 courses, including series readers, like "First lesson of employees in the workplace", "Care of our hearts", "Permanent residents of modern urban civilization of modern consciousness", "Learn survival and development", "Out school youth handbook", "Civilized Manners", "Home security common senses", "Citizen Practical English Course". These courses have rich content, cover wide range, and strong local characteristics, initially formed to meet the new requirements of the new citizens' education curriculum.

\section{Carry Out Educational Training, Change the Cultivation Standard to New Citizen Quality}

The first is carry out the social humanistic quality training, including enhance cultural quality, raise awareness of law, enhance city and home awareness and promote safety awareness. The second is to carry out training to promote capability of seeking and creating employment. The third is to carry out educational background upgrade education. 12 years of education has been popularized. The popularity rate of adult high school and technical secondary school has reached $97 \%$ in the household population between 18 to 35years old. Residents from "Village-to-Community" could get full tuition subsidies if they participate and obtain college or 
bachelor's degree. From 2008 to 2013, it has been paid tuition subsidies for about 52.262 million.

\section{Third, Strengthen Responsibility Consciousness, Strong Push by Government}

Bao'an District takes the new citizens quality enhancement as an important part of people livelihood project. Over the years, it has been a strong push forward, perseverance and continuously deepening, and sustainable development. The first is to strengthen the overall planning. Through deep research, long-term development programs have been set up; establish quality engineering leadership team meetings, joint meeting and expert advisory committee systems, regularly study and solve major issues; develop annual work plans and work programs, and clear long-term and short-term goal, mission, priorities in new citizens education. A series of policy document to upgrade the quality of migrant workers and residents provide a strong guarantee for the sustainable development and effectively improve the pertinence and pragmatically of the new citizens' education. The second is to strengthen management operation. A level three working mechanism including district, department and street was set up to form new system for the new citizens' education with co-ordinate deployment in district, division of labor in department and implement the plan vigorously in street. District professional ability training base was constructed, community education station was set up in 124 community regions and fixed educational sites were built more than 200 square meters in community education stations. The third is to strengthen human and financial investment. Bao'an District has 30 community education specialists, 188 full-time management cadres and 1,180 part-time teachers by 2013 . At the same time, the build of volunteers' team is also strengthened and the perennial volunteers for new citizens' education services are maintained at more than 5,000 persons. Special funds for quality project is also set up and thirty and forty millions yuan per year is scheduled to the work of people quality promotion. The forth is government purchase of services. Now, all employment and entrepreneurship, labor workers vocational skills training projects in residents were included in the government procurements. The fifth is the implementation of monitoring and evaluation. Bao'an District first carried out the supervision and evaluation of "Featured Community Education Station" in china, adhered to overall strategy of supervisor unified planning, classification guidance, advancing by layers and integral development in community education, established incentive mechanism for the relationship between supervise the evaluation results and community workstation performance and rewarded excellent communities. For seven years, more than 70 "special community education stations" and "modernization demonstration education stations" have been selected and effectively promoted community residents quality.

\section{Summary}

Although Bao'an District has done lots of work in the comprehensive implementation of quality education and develop new citizens' quality education, remarkable achievements have made. However, the new citizens' quality education with rich connotation and vast system is a system engineering which cannot be achieved overnight. The objective requirements should keep pace with the times and its connotation and extension should also continue to expand and promotion. Therefore, we must obey the rule of routinization,

long-standing and optimization. In recognition of this fact, Bao'an District government has invested 120 million yuan to build more than 32,000 square meters 'Bao'an District Citizens 
quality education school". At the same time, they also started the research projects on "community education and long-term development plan", to further plan a new round of blueprint on community education and new citizens' quality education, fight hard for large upgrading in citizen quality and make a due contribution to promote the construction of "new Bao'an District with modernization and internationalization.

\section{References}

[1] Y. Li, New citizens cultivating way research, J. Chongqing Three-Gorges University. 26 (2011) 133-138. (In Chinese)

[2] H.L. Ding, Y.Y. Zhu, Improving the Quality of New Citizen in Urbanization, J. Jiangsu Teachers University of Technology. 23(2008) 99-102. (In Chinese)

[3] L. Si, X.F. Liu, A survey of and Thinking on New Urban Residents in Changshu, J. Changshu Institute of Technology. 22(2008) 112-118. (In Chinese)

[4] J. Wen, Farmers "ends" and the role of new citizen community "reengineering"-A case study of Shanghai suburb farmers' urbanization, Social Sci. Res., 2(2009). (In Chinese)

[5] X.J. Chen, Create a civilized city should focus on improving citizens' quality, Hunan Social Sci., 1999(03):75-7. (In Chinese) 